\title{
CYTOLOGICAL AND BACTERIOLOGICAL EVALUATION OF TRANSENDOSCOPIC GUTTURAL POUCH LAVAGES IN CLINICALLY HEALTHY HORSES
}

\author{
Olga Dobesova ${ }^{*}$ and Barbora BezdeKova \\ Equine Clinic, Faculty of Veterinary Medicine, University of Veterinary and \\ Pharmaceutical Sciences, Palackého 1/3, 61242 Brno, Czech Republic
}

(Received 4 February 2016; accepted 4 May 2016)

\begin{abstract}
Thirty-eight guttural pouch lavages from 19 clinically healthy horses were collected transendoscopically. Cytological examination and bacteriological culture of the samples were carried out. All 38 lavages assessed for cytology contained less than five per cent neutrophils and could be termed as cytologically 'normal'. In none of the lavages did the neutrophil count vary between five and 25 per cent or exceed 25 per cent, which are the borderlines for being termed 'reactive' or 'pathological', respectively. Epithelial cells were the most commonly represented cell type in all lavages. Bacteriological culture was positive in 16 out of 38 lavages, but specific pathogenic bacteria were not cultivated in any of them, and only transient microflora was present. Although the relationship between the presence of specific bacteria, neutrophil count and total cell count could not be statistically evaluated due to the absence of 'reactive' and 'pathological' lavages, transendoscopic lavage appears to be a reliable method for obtaining a sample for bacteriological culture.
\end{abstract}

Key words: Horse, guttural pouch, transendoscopic lavage, cultivation, transient microflora

When dealing with a horse suffering from upper or lower airway disease involving the guttural pouches, endoscopy is suitable for direct visualisation of the respiratory tract as well as for sampling and microbiological examination. Its importance can be illustrated when considering the silent carriers of strangles (Streptococcus equi ssp. equi), in which the guttural pouches have been shown to be a common site of latent infection (Newton et al., 1997; Fintl et al., 2000).

Guttural pouch lavages are among the fundamental methods used for obtaining a liquid sample from this unique horse organ. Percutaneous washes of the guttural pouches were previously described by Chiesa et al. $(1999 a, b, 2002)$ as a useful, minimally invasive direct needle sampling procedure with minimal risk of bacterial or cell contamination which might accompany scope insertion. Thus,

*Corresponding author; E-mail: oli.dobesova@seznam.cz; Phone: 00420-777887955; Fax: 00420-541562395 
the results should represent the real cytological and microbiological profile of horse guttural pouches. However, transendoscopic washes of the guttural pouch have been used more often in practice, and this technique is part of the routine evaluation of equine upper airway disorders. There is a scarcity of published data regarding cytological and microbiological results from transendoscopic guttural pouch lavage in healthy horses.

The purpose of this research was to evaluate results obtained by transendoscopic guttural pouch lavage and thus provide essential knowledge on the normal cytological and microbiological parameters of the guttural pouches during standard endoscopic investigation.

\section{Materials and methods}

\section{Selection of horses for the study}

Nineteen horses without any clinical signs of respiratory disorders in their recent history were included in the study. None of the animals showed any signs of disease during clinical examination. The horses were of different breeds (14 warmbloods, five thoroughbreds), both genders (nine geldings, seven mares, three stallions), and were aged between one and 17 years (mean age: 8.4 years, SD: 4.73). They were used for a variety of activities. At the time of sampling all the horses had been stabled under the same conditions in the clinic, in individual boxes without access to pasture, for at least one week. Hay was offered from the ground and water was available ad libitum. Prior to sampling none of horses were given any medication, and routine haematology was performed to exclude subclinical disease.

\section{Endoscopy and guttural pouch lavage}

Endoscopic examination of the upper airways was carried out on each horse, standing and under short-time sedation using a combination of xylazine (Xylapan ${ }^{\circledR}$, Vétoquinol, France; $0.5 \mathrm{mg} / \mathrm{kg}$ bw) or detomidine $\left(\right.$ Cepesedan ${ }^{\circledR} \mathrm{RP}$, CP-Pharma, Germany; $0.01 \mathrm{mg} / \mathrm{kg}$ bw) with butorphanol (Torbugesic ${ }^{\circledR}$, Fort Dodge Inc., USA; $0.01-0.02 \mathrm{mg} / \mathrm{kg} \mathrm{bw}$ ), depending on the character and excitability of the particular horse. During the sampling procedure the horse's head was held above wither height to prevent outflow of the lavage fluid. A videoendoscope of $9 \mathrm{~mm}$ in diameter and $140 \mathrm{~cm}$ working length plus a metal introducer were sterilised in glutaraldehyde solution $\left(\mathrm{Cidex}^{\circledR} \mathrm{OPA}\right.$, Johnson \& Johnson, USA) and then thoroughly flushed with water. After inserting the endoscope into the guttural pouch, a sterile polyethylene transendoscopic catheter was led inside the working channel of the scope. Subsequently each pouch was flushed with $25 \mathrm{~mL}$ of saline solution and the fluid (at least $10 \mathrm{~mL}$ ) was aspirated back into 
the syringe. Both pouches were flushed from the same side in order to reduce possible contamination of the scope; only the polyethylene catheter was replaced by a sterile one before sampling from the second pouch. The samples obtained were injected into sterile tubes for further microbiological examination and ethylenediamine-tetraacetic acid (EDTA) tubes for cytology, and were immediately sent to the laboratory.

\section{Cytology and bacteriology}

Total cell count was measured using a Celltac haemocytometer (Nihon Kohden, Japan). Samples were further evaluated after centrifugation at $3000 \mathrm{rpm}$ for $5 \mathrm{~min}$. The precipitate was smeared on slides, air-dried and stained with hemacolor (Hemacolor ${ }^{\mathbb{B}}$, Merck Chemicals, Germany) and a differential cell count was made for a total of 100 cells because of the low cellularity of the samples. The cytological profile, the presence of bacteria and the amount of mucus were also noted. Lavages were then classified for comparative purposes according to Chiesa et al. $(1999 a, b)$ as either normal (having less than 5\% neutrophils/ 100 cells), reactive ( $5 \%$ to $25 \%$ neutrophils), or pathological (more than $25 \%$ neutrophils).

Samples for bacteriology were diluted at various ratios with phosphatebuffered saline and cultured on selective blood agar plates with or without Streptococcus Selective Supplement, or MacConkey agar and Selective Broth Medium. Plates were cultivated for $24 \mathrm{~h}$ at $37^{\circ} \mathrm{C}$; only aerobic cultures were made. Bacterial growth was examined after 24 and $48 \mathrm{~h}$. If bacterial growth was present, the colonies were further subcultured on blood agar. Bacterial species were identified according to the routine methods of the particular laboratory.

The statistical significance of differences in selected data was evaluated by Fisher's exact test.

\section{Results}

\section{Endoscopy and sampling}

In seventeen out of the 19 examined horses the guttural pouches were without endoscopically visible pathologies. Follicular lymphoid hyperplasia in the left pouch was found in horse no. 14 and small-sized melanotic lesions were present in both pouches of the grey horse no. 16. Sampling was performed as described without any complications. A total of 38 lavages were collected from the guttural pouches of the horses examined.

\section{Cytology}

The total cell count, the numbers of neutrophils, lymphocytes, monocytes/ macrophages, eosinophils and epithelial cells, the amount of mucus and the pres- 
ence of bacteria were recorded. In both lavages of horse no. 13 there was an insufficient number of cells for differential cell counts from 100 cells and thus these samples were excluded from cytological evaluation. All of the 36 lavages evaluated cytologically $(100 \%)$ were classified as normal on the basis of the neutrophil count. None of the lavages could be termed as reactive or pathological. Epithelial cells were the predominant cell type in the lavages and were represented by ciliated columnar and non-ciliated cuboidal cells. In addition, there were some non-differentiated epithelial cells with/without a nucleus, which could not be precisely identified and could represent damaged epithelial or superficial squamous cells from the pharynx (Table 1).

The amount of mucus was described as low (grade 1), medium (grade 2), or high (grade 3). Low and medium amounts of mucus (grades 1 and 2) were present in 8 lavages $(21.1 \%)$ and extracellular bacteria in 10 lavages $(26.3 \%)$. High amounts of mucus (grade 3), bacterial phagocytosis and fungi were not observed cytologically in any sample.

\section{Bacteriology}

Bacteriological cultivation was positive in 16 lavages $(42.1 \%$ of all samples) taken from nine horses. In two of them only one pouch was infected. Twenty-two samples (57.9\% of all samples) showed no bacterial growth (Table 2).

Specific pathogenic bacteria were not identified in any of the 16 samples found positive by bacterial culture, and only contaminating transient microflora could be cultured. Contaminants were considered to be bacterial species [including Aeromonas sp., Flavobacterium sp., Micrococcus sp., Pseudomonas sp., $\alpha-$ haemolytic streptococci, coagulase-negative staphylococci, Staphylococcus sp., coagulase-positive staphylococci (S. intermedius) and oxidase-negative bacilli] which showed growth between $10^{2}$ and $10^{6} \mathrm{cfu} / \mathrm{mL}$, but with regard to the general status of the horses were not associated with any cytological signs of active inflammation in the guttural pouches and were not regarded as pathogens. When culture from one guttural pouch was positive for bacterial growth, the possibility of a positive culture from the second pouch of the same horse was 0.055 , which did not come close to the level of statistical significance.

From Table 2 we can conclude that in none of the 16 positive lavages was the cultivation finding accompanied by an increase in neutrophil count. The total cell count was increased in the left guttural pouch of horse no. 3, but no neutrophils were recorded and only transient bacteria were found. 
Table 1

Cytological examination of left/right guttural pouch lavages and differential count of 100 cells

\begin{tabular}{|c|c|c|c|c|c|c|c|c|c|c|}
\hline Lavage & TCC & $\mathrm{Neu}$ & $\begin{array}{l}\text { Mon/ } \\
\text { Mac }\end{array}$ & Eos & Lymph & $\mathrm{CCC}$ & NCC & $\mathrm{NC}$ & Mucus & Bacteria \\
\hline 1.1 & 400 & 3 & & & 1 & 75 & 20 & 1 & & $\mathrm{EC}$ \\
\hline 1.2 & 100 & 1 & & & & 83 & 13 & 3 & & \\
\hline 2.1 & 0 & 2 & 1 & & 3 & 54 & & 40 & + & \\
\hline 2.2 & 0 & & & & & 78 & 22 & & & \\
\hline 3.1 & 800 & & & & & 70 & 30 & & + & \\
\hline 3.2 & 300 & & & & & 41 & 55 & 4 & & \\
\hline 4.1 & 0 & 3 & & & 2 & 65 & 30 & & + & \\
\hline 4.2 & 200 & & 1 & & & 59 & 40 & & & \\
\hline 5.1 & 0 & & & & & & & 100 & & EC clusters \\
\hline 5.2 & 100 & & & & & & & 100 & & EC clusters \\
\hline 6.1 & 0 & & & & & 12 & 1 & 87 & & \\
\hline 6.2 & 100 & & & & 2 & 78 & 20 & & & \\
\hline 7.1 & 0 & & & & & & & 100 & & \\
\hline 7.2 & 0 & & & & & & & 100 & & \\
\hline 8.1 & 100 & 5 & 1 & 1 & 1 & 59 & 33 & & + & \\
\hline 8.2 & 100 & 2 & 1 & & & 68 & 27 & 2 & & $\mathrm{EC}$ \\
\hline 9.1 & 100 & 1 & 1 & & 3 & 83 & 12 & & & \\
\hline 9.2 & 100 & & 1 & & & 74 & 23 & 2 & & \\
\hline 10.1 & 100 & & & & 1 & 72 & 27 & & & \\
\hline 10.2 & 0 & & & & 1 & 49 & 50 & & & $\mathrm{EC}$ \\
\hline 11.1 & 100 & & & & & 96 & 1 & 3 & + & EC clusters \\
\hline 11.2 & 200 & & & & & 91 & 9 & & & \\
\hline 12.1 & 100 & & & & & 97 & 1 & 2 & & \\
\hline 12.2 & 200 & & & & & 89 & 11 & & + & \\
\hline 13.1 & 100 & & & & & 7 & & 2 & & \\
\hline 13.2 & 100 & & & & & 5 & 4 & & & \\
\hline 14.1 & 400 & & & & 1 & 70 & 29 & & & \\
\hline 14.2 & 100 & & & & & 47 & 53 & & & \\
\hline 15.1 & 0 & & & & & 95 & 2 & 3 & + & $\mathrm{EC}$ \\
\hline 15.2 & 100 & & & & & 92 & 6 & 2 & & $\mathrm{EC}$ \\
\hline 16.1 & 0 & & & & & & 2 & 98 & & \\
\hline 16.2 & 0 & & & & & & & 100 & & $\mathrm{EC}$ \\
\hline 17.1 & 0 & & & & & & & 100 & & $\mathrm{EC}$ \\
\hline 17.2 & 0 & & & & & 3 & & 97 & & \\
\hline 18.1 & 100 & & & & & 32 & & 68 & & \\
\hline 18.2 & 400 & & & & 1 & 93 & 4 & 2 & & \\
\hline 19.1 & 200 & & 3 & & 1 & 81 & 11 & 4 & & \\
\hline 19.2 & 0 & & & & & 97 & 2 & 1 & ++ & \\
\hline
\end{tabular}

$\mathrm{TCC}=$ total cell count $/ 1 \mu \mathrm{L}, \mathrm{Neu}=$ neutrophils, $\mathrm{Mon} / \mathrm{Mac}=$ monocytes $/$ macrophages, Eos $=$ eosinophils, $\mathrm{Lymph}=$ lymphocytes, $\mathrm{CCC}=$ ciliated columnar epithelial cells, $\mathrm{NCC}=$ non-ciliated cuboidal epithelial cells, $\mathrm{NC}=$ further non-differentiated epithelial cells, $\mathrm{EC}=$ extracellular 


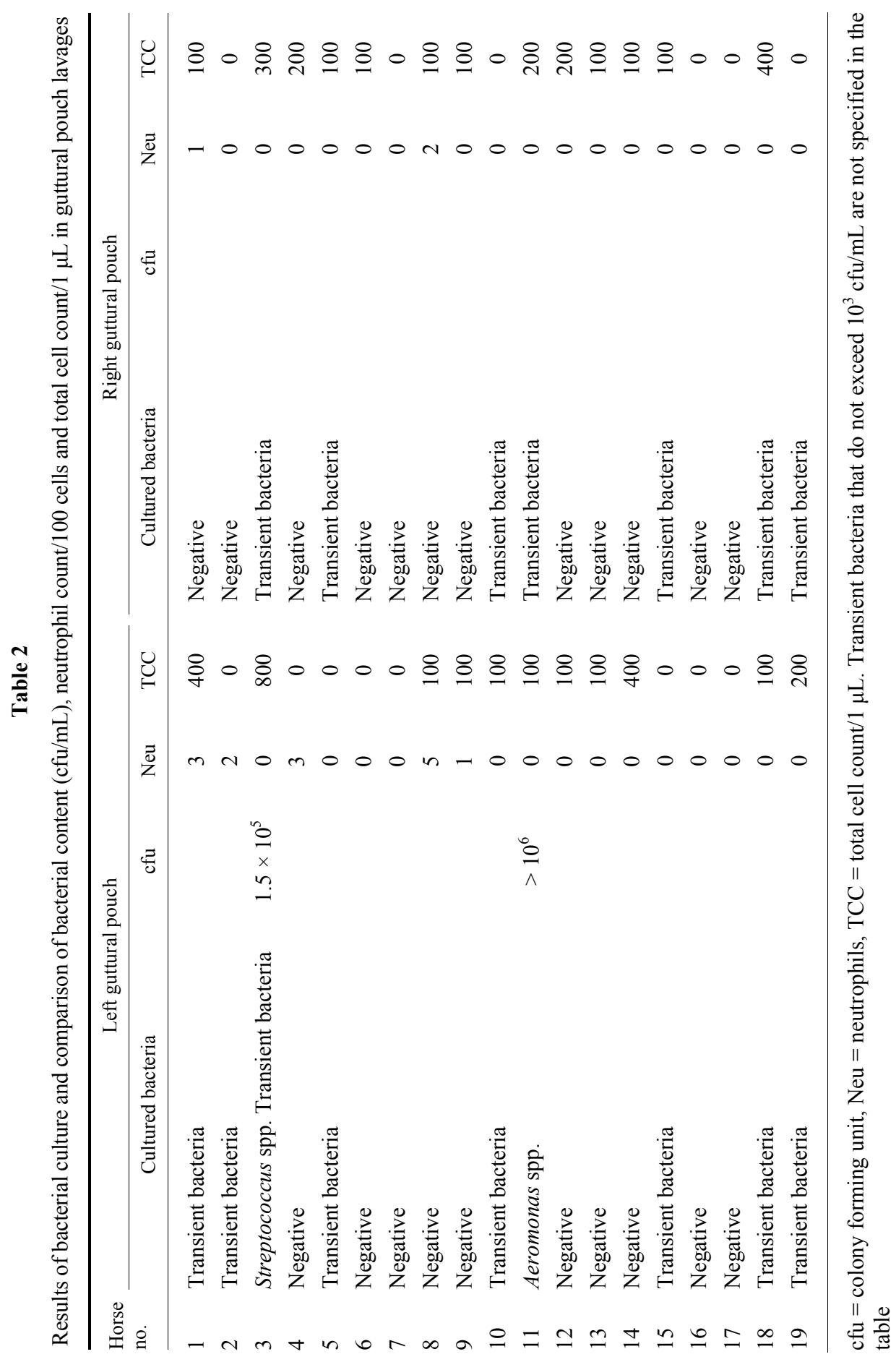




\section{Discussion}

The motivation for carrying out this study was the relatively limited number of studies published on the topic of guttural pouch cytology (Chiesa et al., 1999a,b, 2002), apart from studies concerning the detection of Streptococcus equi ssp. equi in the guttural pouches of horses with strangles infection (Wood et al., 1993; Fintl et al., 2000). Our study summarises the endoscopic findings in guttural pouches of healthy horses and deals with the cytological and microbiological examination of guttural pouch lavages obtained transendoscopically.

Despite the variability in age and breed of the selected horses, the results obtained showed higher uniformity in certain parameters than had been found by other authors, e.g. Chiesa et al. $(1999 a, b)$.

Endoscopy was performed on all horses according to the standard methods (Edwards and Greet, 2007). The method of sedation and restraint of the horse did not affect the quality of samples. However, increased excitability (movement) of individual horses while the endoscope was passed through the nasal passages could lead to possible contamination of the end of the scope with epithelial cells and upper airway bacteria.

Although the amount of aspirated fluid differed between horses, presumably this had no influence on cellularity of the lavage because sample dilution was the same for the entire sample content from each pouch. Chiesa et al. (1999a) reported widely variable cellularity in individual samples obtained by percutaneous lavage. The highest cellularity was in the guttural pouch of a less co-operative horse, and so we can speculate that the total cell count was influenced by the sampling technique (more frequent contact of the scope with the mucosa of the pouch and possible brushing off of epithelial cells).

No specific pathology was obvious in the guttural pouches of any of the horses during endoscopy. The exception was a horse with a low degree of lymphoid hyperplasia which in our study did not affect the neutrophil count. Multifocal areas of melanosis visible in the roof of both pouches of another horse did not seem to influence the condition of the upper airways as reported by Fintl and Dixon (2001) in white horses.

Studies dealing with the differential cell count in washes of various parts of the airways assessed possible pathologies according to the number of neutrophils as their increase may be connected with the presence of bacteria (Whitwell and Greet, 1984; Chiesa et al., 1999a,b, 2002) as well as allergens and viruses (Burrell et al., 1996). The reactivity of lavages in our study was classified according to Chiesa et al. $(1999 a, b)$ for simplicity and comparative purposes. Our results showed 36 cytologically normal, no reactive and no pathological lavages. These results differ from those obtained by Chiesa et al. (1999a), where only 24 out of 54 percutaneous washes were cytologically normal. The same authors mentioned that the increase of neutrophil count in samples logically leads to a 
reduction in the numbers of epithelial cells and is associated with the presence of bacteria and mucous content. As in our study the transendoscopic lavage method was used, it is possible that the relative increase in the proportion of epithelial cells was due to contact of the scope with the mucosa of the upper airways during its insertion. In our opinion, the percutaneous wash technique is more invasive and involves the risk of vessel or nerve injury in the pouch wall. Nevertheless, its indisputable advantage is that it samples directly from the pouch cavity, thus avoiding further contamination and abrasion of epithelial cells by the scope. Due to the fact that in our case none of the lavages was reactive or pathological, it was impossible to assess the proportion of individual cell types statistically.

Bacterial cultivation was positive in less than half of the samples. Streptococcus spp. are common pathogens present in the guttural pouches of horses (Newton et al., 1997; Laus et al., 2007). In our study no horse had a specific respiratory pathogen in its guttural pouch. A Streptococcus sp. was cultivated from a single horse, but this sample contained a low grade of mucus and the number of neutrophils in this lavage did not indicate an inflammatory process but more probably a contamination by upper airway microflora. $\mathrm{N}$ carrier of strangles was found in this study.

In all other cases only transient bacteria and bacteria with questionable pathogenicity for horses were found. Based on the study of Sweeney et al. (1985) regarding the division of bacterial species from tracheobronchial aspirates into pathogenic and transient, we would have to perform subsequent bacterial species typing, e.g. Pseudomonas. However, Ainsworth and Cheetham (2010) consider bacteria of the genus Pseudomonas to be the most common environmental contaminants in endoscopy, which rarely cause respiratory infections in horses.

The importance of individual bacterial isolates is not always obvious. According to Hodgson and Hodgson (2007), only bacterial counts higher than $10^{3} \mathrm{cfu} /$ $\mathrm{mL}$ in tracheal aspirates from the cranial thoracic aperture should be considered to be significant and the cultivated bacteria are only one of the probable causes of infection. In our study the bacterial counts reached a value of $10^{6}$, e.g. for Aeromonas. In this case the bacteria were not found intracellularly and their presence was not associated with an increase in inflammatory cell counts. It is also questionable whether a value of $10^{3} \mathrm{cfu} / \mathrm{mL}$ can be considered critical in this part of the upper airways, including the guttural pouches, since this region of the respiratory tract is more exposed and thus a higher capture rate of common microflora can be expected. Sweeney et al. (2005) reported that less than $10^{6} \mathrm{cfu}$ of intranasal Streptococcus equi inocula were not effective in causing any clinical infection, because the microorganisms could be efficiently removed by mucociliary clearance. To the best of our knowledge, quantification of bacteria in the guttural pouches of horses has not been reported yet.

Chiesa et al. (1999a) reported the isolation of bacteria in 59\% of guttural pouch lavages despite using the percutaneous sampling technique and thus 
avoiding possible contamination by the upper airway microflora. Even in that study mainly transient, non-pathogenic bacteria were cultivated. From the culture-positive lavages, 10 were cytologically normal, five reactive and 17 pathological, and a correlation was found between positive bacterial cultivation and neutrophil counts. Since only four out of 32 positive lavages contained bacteria with recognised pathogenicity, the increased neutrophil count may not necessarily be connected with the presence of pathogens. Chiesa et al. (1999a,b) also found a negative correlation between the neutrophil count and the level of exercise. Our horses were stabled and did not perform before or during the study; however, the neutrophil count was lower. The guttural pouch orifice opens and drains during swallowing and low head position, which could occur more often in our animals.

Cytological examination of a sample smear can assist in distinguishing contaminants and pathogens, since inflammation-causing bacteria may be located intracellularly due to active phagocytosis. However, the absence of bacteria does not exclude infection. In a case of toxin production, degenerative neutrophils could be observed due to the effect of the toxin (Clinkenbeard et al., 2002). The relationships between neutrophil counts, results of bacterial culture and lavage cellularity could not be statistically evaluated due to the absence of reactive and pathological lavage samples in our study.

We can conclude that for a thorough evaluation of bacterial cultures from equine transendoscopic guttural pouch washes a knowledge of the common bacterial population in normal horses is necessary. The neutrophil count in guttural pouch lavages should be interpreted with caution because their increase is not necessarily connected with the presence of pathogens and should be assessed in correlation with possible clinical signs of a disease.

\section{Acknowledgements}

We would like to acknowledge all colleagues from the Equine Clinic, University of Veterinary and Pharmaceutical Sciences Brno, Czech Republic, for their help with collecting data for this study.

This work was supported by grants IGA 1/2011/FVL and 46/2012/FVL from the University of Veterinary and Pharmaceutical Sciences Brno.

\section{References}

Ainsworth, D. M. and Cheetham, J. (2010): Disorders of the respiratory system. In: Reed, S. M., Bayly, W. M. and Sellon, D. C. (eds) Equine Internal Medicine, 3rd edition. Saunders Elsevier, St. Louis. pp. 325-327. 
Burrell, M. H., Wood, J. N. L. and Whitwell, K. E. (1996): Respiratory disease in Thoroughbred horses in training: the relationships between disease and viruses, bacteria and environment. Vet. Rec. 139, 308-313.

Chiesa, O. A., Cuenca, R., Mayayo, E., Guarro, J., Santamaria, J. and Stchigel, A. M. (2002): Cytological and microbiological findings in guttural pouch lavages of clinically normal horses with head restraint. Aust. Vet. J. 80, 234-238.

Chiesa, O. A., Garcia, F., Domingo, M. and Cuenca, R. (1999b): Cytological and microbiological results from equine guttural pouch lavages obtained percutaneously: correlation with histopathological findings. Vet. Rec. 144, 618-621.

Chiesa, O. A., Vidal, D., Domingo, M. and Cuenca, R. (1999a): Cytological and bacteriological findings in guttural pouch lavages of clinically normal horses. Vet. Rec. 144, 346-349.

Clinkenbeard, K. D., MacAllister, C. G., Cowell, R. L., Tyler, R. D. and Beaudin, S. (2002): Oral and nasal cavities, pharynx, guttural pouches and paranasal sinuses. In: Cowell, R. L. and Tyler, R. D. (eds) Cytology and Hematology of the Horse, 2nd edition. American Veterinary Publications, St. Louis. pp. 65-72.

Edwards, G. B. and Greet, T. (2007): Disorders of the guttural pouches (auditory tube diverticuli). In: McGorum, B. C., Dixon, P. M., Robinson, N. E. and Schumacher, J. (eds) Equine Respiratory Medicine and Surgery. Saunders Elsevier, Philadelphia. pp. 419-436.

Fintl, C. and Dixon, P. M. (2001): A review of five cases of parotid melanoma in the horse. Equine Vet. Educ. 13, 17-24.

Fintl, C., Dixon, P. M., Brazil, T. J., Pirie, R. S. and McGorum, B. C. (2000): Endoscopic and bacteriological findings in a chronic outbreak of strangles. Vet. Rec. 147, 480-484.

Hodgson, J. and Hodgson, D. R. (2007): Collection and analysis of respiratory tract samples. In: McGorum, B. C., Dixon, P. M., Robinson, N. E. and Schumacher, J. (eds) Equine Respiratory Medicine and Surgery. Saunders Elsevier, Philadelphia. pp. 119-150.

Laus, F., Preziuso, S., Spaterna, A., Beribe, F., Tesei, B. and Cuteri, V. (2007): Clinical and epidemiological investigation of chronic upper respiratory disease caused by beta-hemolytic streptococci in horses. Comp. Immunol. Microb. 30, 247-260.

Newton, J. R., Wood, J. L. N., Dunn, K. A., DeBrauwere, M. N. and Chanter, N. (1997): Naturally occurring persistent and asymptomatic infection of the guttural pouches of horses with Streptococcus equi. Vet. Rec. 140, 84-90.

Sweeney, C. R., Beech, J. and Roby, K. A. W. (1985): Bacterial isolates from tracheobronchial aspirates of healthy horses. Am. J. Vet. Res. 46, 2562-2565.

Sweeney, C. R., Timoney, J. F., Newton, J. R. and Hines, M. T. (2005): Streptococcus equi infections in horses: Guidelines for treatment, control, and prevention of strangles. J. Vet. Intern. Med. 19, 123-134.

Whitwell, K. E. and Greet, T. R. C. (1984): Collection and evaluation of tracheobronchial aspirates of healthy horses. Equine Vet. J. 16, 499-508.

Wood, J. L., Dunn, K., Chanter, N. and DeBrauwere, N. (1993): Persistent infection with Streptococcus equi and the epidemiology of strangles. Vet. Rec. 133, 375. 